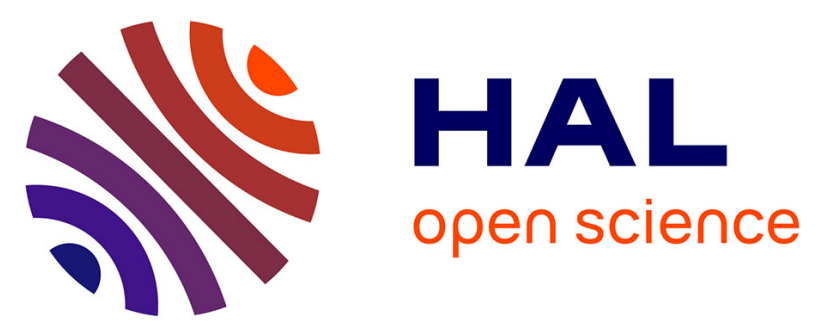

\title{
Design and Implementation of Monitoring and Early Warning System for Urban Roads Waterlogging
}

\author{
Yang Liu, Mingyi Du, Changfeng Jing, Guoyin Cai
}

\section{To cite this version:}

Yang Liu, Mingyi Du, Changfeng Jing, Guoyin Cai. Design and Implementation of Monitoring and Early Warning System for Urban Roads Waterlogging. 8th International Conference on Computer and Computing Technologies in Agriculture (CCTA), Sep 2014, Beijing, China. pp.610-615, 10.1007/9783-319-19620-6_68. hal-01420278

\section{HAL Id: hal-01420278 \\ https://hal.inria.fr/hal-01420278}

Submitted on 20 Dec 2016

HAL is a multi-disciplinary open access archive for the deposit and dissemination of scientific research documents, whether they are published or not. The documents may come from teaching and research institutions in France or abroad, or from public or private research centers.
L'archive ouverte pluridisciplinaire HAL, est destinée au dépôt et à la diffusion de documents scientifiques de niveau recherche, publiés ou non, émanant des établissements d'enseignement et de recherche français ou étrangers, des laboratoires publics ou privés. 


\title{
Design and Implementation of Monitoring and Early Warning System for Urban Roads Waterlogging
}

\author{
Yang Liu ${ }^{1,2, a *}$, Mingyi Du ${ }^{1,2, b}$, Changfeng Jing ${ }^{1,2, c}$, Guoyin Cai1 ${ }^{1,2, d}$ \\ ${ }^{1}$ School of Geomatics and Urban Information, Beijing University of Civil Engineering and \\ Architecture, Beijing 100044, China; ${ }^{2}$ The Key Laboratory for Urban Geomatics of National \\ Administration of Surveying, Mapping and Geoinformation, Beijing university of Civil \\ Engineering and Architecture, Beijing 100044, China \\ aliuyang@bucea.edu.cn, ${ }^{\text {b dumingyi@bucea.edu.cn, }}$ ㄹingcf@, bucea.edu.cn, \\ dcgyin@,bucea.edu.cn
}

\begin{abstract}
Waterlogging happens almost in every rainstorm in city roads and the concave type of overpasses in Beijing. It causes to serious effect for the security of people's daily travel. For resolving this kind of problem, this paper designed a monitoring network by water level sensors and other technologies of internet of things, and developed a monitoring and early warning system for detecting the real-time information of waterlogging conditions in urban roads. This system can capture the real time information of waterlogging depth, make a fast query statistics for certain road or area, and also provide the short message service for the public. It is very convenient for the managers working in department of flood control and command center to collect the real-time information of waterlogging status around urban roads. This is helpful for the local government to perform the correspondingly emergency plan and issue waterlogging information for the public, so as to reduce the impact on the security of people's travel caused by the suddenly bad weather.
\end{abstract}

Keywords: urban roads waterlogging, monitoring and early warning system, design and implementation, sensors

\section{Introduction}

The speed of city construction has become more and more quickly with the rapid development of urbanization in recent years. As side consequences, the disaster of regional flood in urban areas has increased significantly, and some other weaknesses in city planning, construction and management have been also emerged at the same time [1]. A large number of concave type of overpasses and tunnels have been constructed to alleviate traffic pressure and to ensure travel unimpeded in some megacities such as Beijing and Shanghai[2-4]. A big challenge should be faced by the people working in the department of city flood control because some sudden extreme rainfall weather happens now and then in recent years. For example, the 7 roads were in traffic disruption, the 27 bridges were covered with water, and the traffic was resumed until 6 hours later during the severe natural disaster happened at July, 21, 2012 in Beijing. The main reason for this phenomenon is due to the unreasonable planning of the city drainage system, additionally, there was no systematic monitoring 
for the status of the road waterlogging which caused the delay of the early warning and forecasting because of no real time monitoring and transmission of the data with real time water condition[5-6].

For resolving the above mentioned problems, this paper designed a road waterlogging monitoring network covering the whole Beijing urban areas by means of sensor technology and wireless transmission technology. Based on this network, a road waterlogging monitoring and early warning system was developed. The system can provide real-time information for managers performing decision-making strategy, and offer technical support for the organization of municipal drainage management. This system can be also used to release water monitoring information to the public through the micro-blog and other rapidly updated media, so as to guide the public travel. The monitoring method, system design and implementation were discussed in this paper.

\section{Methods}

As shown in Fig. 1, sensors were installed near the concave type of overpass or lowlying courtyard road where often suffer from waterlogging. Sensors in the whole study areas constitute a waterlogging monitoring network. The mobile GMS/GPRS communication network was used to transmit water information to the monitoring center at certain preset intervals. The road waterlogging monitoring system was developed through the information collected by sensors. The waterlogging locations are displayed in this system. It can be used to query the real-time water information and make an early warning for urban flood. This monitoring system software is installed on the WEB server, which can provide service of real time water information to the public. The workers in department of flood control only needs a computer with internet access to operate the software, realizing the real-time query of road waterlogging, water retention, reminding of early warning, water site inquiries with exceed the standard water, and 12 hours of water values etc..

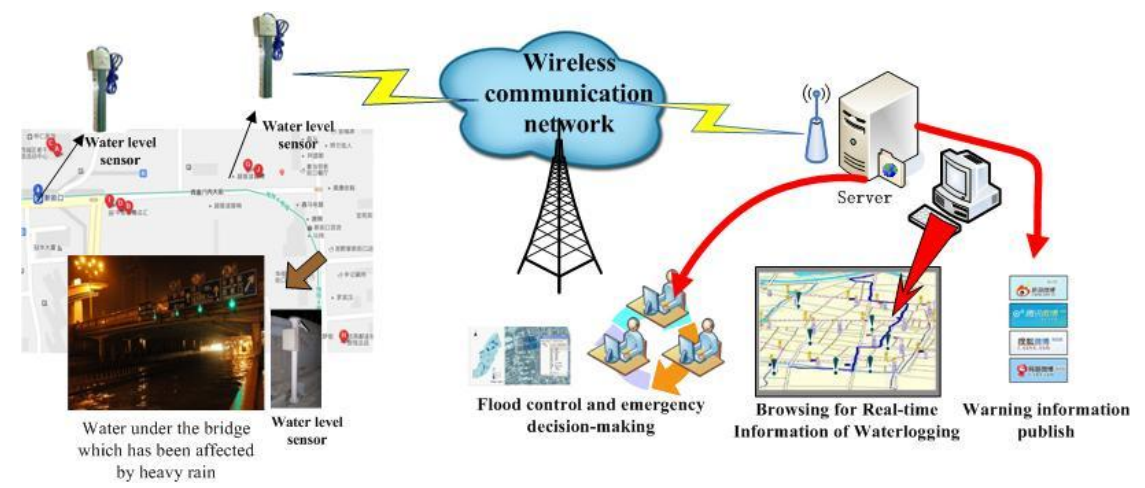

Fig. 1. Schematic diagram of monitoring method for urban roads waterlogging 


\section{System Design}

\subsection{System Architecture}

This system includes two parts, that is, road waterlogging monitoring stations and monitoring center, as shown in Fig. 2.

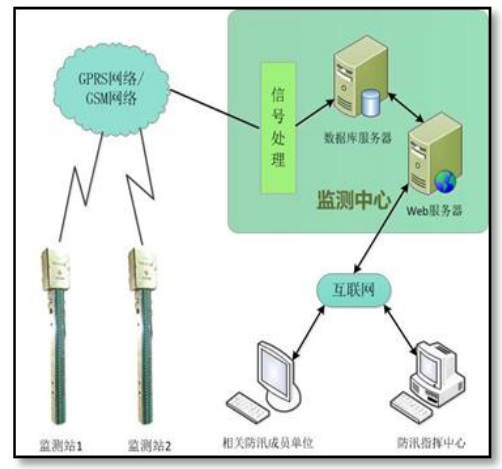

Fig. 2. The system structure diagram

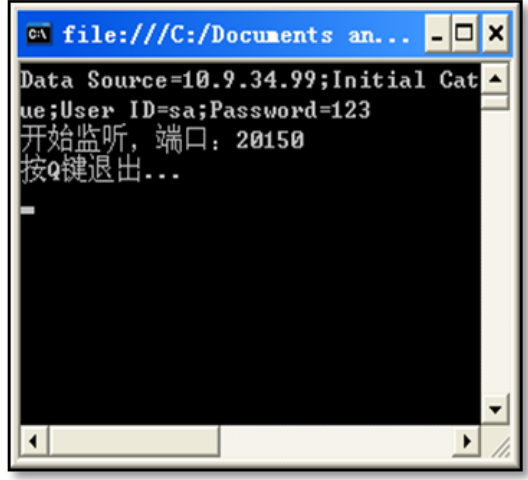

Fig. 3. Data receiving Service

Road waterlogging monitoring station is consists of electronic gauge and wireless terminal, which are responsible for data acquisition and data transmission of real time road waterlogging. Electronic gauge and wireless client machine are the important components of road waterlogging monitoring station. Ectronic gauge is used to collect data of water level. It is equipped with advanced microprocessor chips for digital water level controller, and built-in communication circuit of sensor. It has the characteristics of high reliability and anti-interference performance with measurement accuracy of $1 \mathrm{~cm}$. The wireless client machine: it is used to data transmission. It is a whole new generation of intelligent telemetering terminal through assembling RTU, GPRS/GSM communication module, protection module and the charge controller. It can directly access the 5-10W solar panels or other accords with the power supply voltage requirements.

Monitoring center is responsible for data reception, data processing and data display[7]. It is consists of hardware such as the database server, web server and software such as data receiving software and application software. As shown in Fig.3, the data receiving terminal is responsible for receiving, decoding, checking and storing of the receipted road waterlogging data transmitted by the monitoring network.

\subsection{Core Functions}

This system is an integrated flood control synthetic application system for digital urban which assembles electronic map, real-time water monitoring, early warning analysis. As shown in Fig.4, the core functions of this system can be divided into 3 
major parts, also known as a subsystem. They are water information receiving module, water monitoring and early warning module, and a warning short message service module, each module has its own corresponding function.

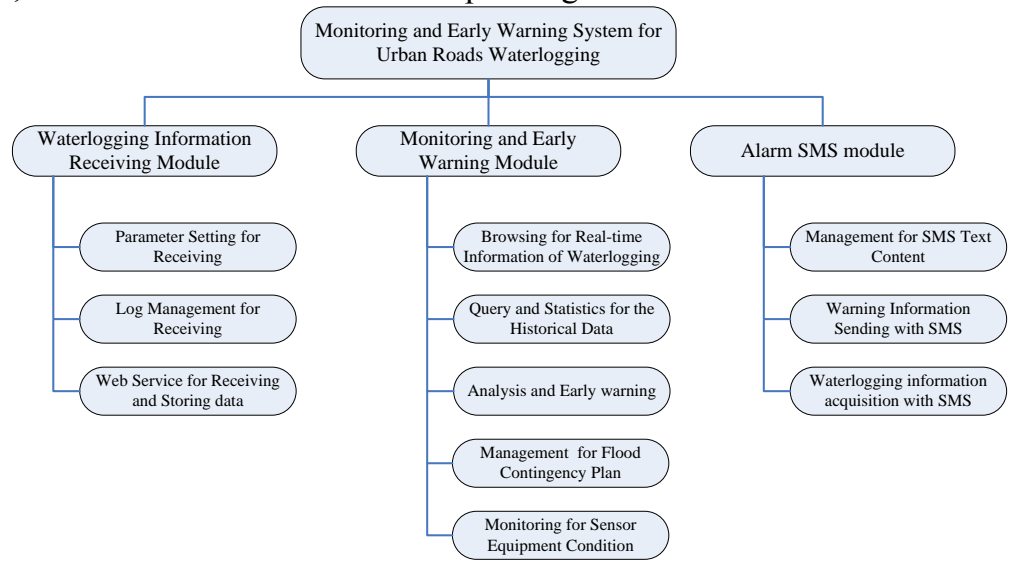

Fig. 4. The core functions of monitoring and early warning system for urban roads waterlogging

\subsection{Road Waterlogging Alert Levels}

There are four alert levels designed in this system. They are blue, yellow, orange and red alert in an ascending order level. The alert level in a single monitoring station is determined by the waterlogging time and water depth. The alert standard for different warning levels is shown in table 1 .

Table 1. The alert level of real-time monitoring data for urban roads waterloggin ( single monitoring site )

\begin{tabular}{ccccc}
\hline The Depth & $\begin{array}{c}5 \mathrm{~cm}- \\
10 \mathrm{~cm}(\mathrm{Ex})\end{array}$ & $\begin{array}{c}10 \mathrm{~cm}- \\
15 \mathrm{~cm}(\mathrm{Ex})\end{array}$ & $\begin{array}{c}15 \mathrm{~cm}- \\
20 \mathrm{~cm}(\mathrm{Ex})\end{array}$ & $>=20 \mathrm{~cm}$ \\
\hline $0-15 \min (\mathrm{In})$ & Yellow alert & Orange alert & Red alert & Red alert \\
$15-30 \min (\mathrm{In})$ & Yellow alert & Orange alert & Red alert & Red alert \\
$30-60 \min (\mathrm{In})$ & Blue alert & Yellow alert & Orange alert & Red alert \\
$>60 \mathrm{~min}$ & Blue alert & Blue alert & Yellow alert & Red alert \\
\hline
\end{tabular}

The synthetic alert in the whole urban region is based on the comprehensive analysis of all the monitoring sites. The alert standard is shown in table 2 .

Table 2. The alert Level of real-time monitoring data for urban roads waterlogging (taking all the monitoring sites into account)

$\begin{array}{ll}\text { The Comprehensive } & \text { The Specific Standards } \\ \text { Alert Level } & \end{array}$




\begin{tabular}{cc}
\hline Blue Alert & $\begin{array}{c}\text { More than } 50 \% \text { of all monitoring sites have issued blue alert; or more than } 30 \% \\
\text { of all monitoring sites have issued yellow alert; or more than } 20 \% \text { of all monitoring } \\
\text { sites have issued orange alert and over. } \\
\text { More than } 80 \% \text { of all monitoring sites have issued blue alert; or more than } 50 \% \\
\text { of all monitoring sites have issued yellow alert; or more than } 30 \% \text { of all monitoring } \\
\text { sites have issued orange alert and over. } \\
\text { All monitoring sites have issued blue alert; or more than } 80 \% \text { of all monitoring } \\
\text { sites have issued yellow alert; or more than } 50 \% \text { of all monitoring sites have issued } \\
\text { orange alert and over. } \\
\text { All monitoring sites have issued yellow alert; or more than } 80 \% \text { of all monitoring } \\
\text { sites have issued orange alert; or more than } 50 \% \text { of all monitoring sites have issued } \\
\text { red alert. }\end{array}$ \\
\hline
\end{tabular}

Water retention alert only relates to the early warning in an individual site. The alert level is issued based on the water level decline rate. The alert standard is shown in table 3 .

Table 3. The alert Level of water retention in urban roads

\begin{tabular}{ccccc}
\hline $\begin{array}{c}\text { Withdrawal } \\
\text { Rates (unit: cm / } \\
\text { hour) }\end{array}$ & $2.0($ In $)-5.0$ & $2.0($ In $)-3.0$ & $1.0($ In $)-2.0$ & $<1.0$ \\
\hline Alert Level & Blue alert & Yellow Alert & Orange Alert & Red Alert \\
\hline
\end{tabular}

\section{System implementation}

City Road Waterlogging Monitoring and warning system is designed as a browser / server (B / S) software system architecture. Flex framework and C\# were used as the programming language, and SQL Server 2008 as the database server. ArcSDE is adopted to store the spatial data, and ArcServer is employed to provide the map service. The interface is shown below, as shown in Fig.5.

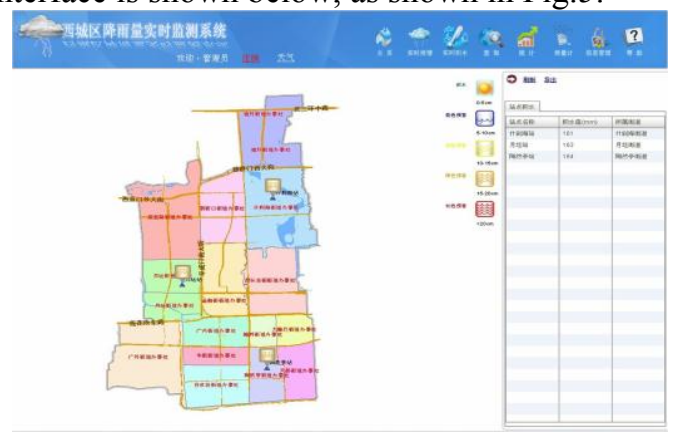

Fig. 5. The Interface of Monitoring and Early Warning System for Urban Roads Waterlogging. 


\section{Conclusions}

With the rapid development of social economy in urban region, the disaster of waterlogging or lost caused by sudden rainstorm or other bad weather might become more and more serious. It makes the managers in department of flood control and command center to collect the correct and real time information of waterlogging much more convenient that the establishment of the monitoring and early warning system [8-9]. This system built by means of sensors not only provide reliable information for the local government to perform some decision-making in flood control and command, but make the working be more of efficiency and the decisionmaking policy be more of scientificalness, so as to guarantee the security of people's daily travel much more better.

\section{Acknowledgment}

The research performed is supported by the National Natural Science Foundation of China (No. 41101444), Beijing Nova Program (No. Z121106002512025), and is partially funded by Beijing Municipal Organization Department talents project(No.2012D005017000001). The work was performed under the Key Laboratory for Urban Geomatics of National Administration of Surveying, Mapping and Geoinformation (No. 20111210N). We wish to thank Guoyin Cai for his careful proofreading of the manuscript.

\section{References}

1. Z.C. Xia, X.J. Zhong, F. Ruan, et al. Design of monitoring and alarm system for city stagnant water [J]. Electronic Test, 2013, No.5, pp. 56-57, 61.

2. S.L. Wan, L.Y. Zuo, S.J. Wang. The design of urban road in Laixi water monitoring system [J]. Shandong Water Resources, 2011, No.1, pp. 61-62, 65.

3. C.L. Pan. The design of city overpass water automatic monitoring system in Shanghai [J]. Water Resources Informatization, 2010, No.3, pp42-44.

4. H.J. Xu, L.H. Liu. Application of electronic gauge in the city road water monitoring system [J]. Water Resources Informatization, 2010, No.3, pp45-47, 57.

5. R.Y. Zhou, F. Bai, H.L. Sui, et al. Urban waterlogging remote monitoring system based on embedded [J]. Water Conservancy Science and Technology and Economy, 2013, No.4, pp109-112.

6. Ramos MH, Leblois E, Creutin JD, et al. Form point to areal rainfall: linking the different approaches for the frequency characterisation of rainfalls in urban areas[J]. Water Science and Technology, 2006, 54(6/7): 33-40.

7. Larry Caudle. Flood waring[J]. Roads \& Bridges, 2010, 48(6): 16-17.

8. Ranhang Zhao. Safety evaluation of Urban Flood Control System Based on Variable fuzzy pattern recognition[C]. //Micro Nano Devices, Structure and Computing Systems. 2011: 264-269. 
9. Sultana Taufka Akter MD, Zahurul Islam, Mohammad Najmul Islam, et al. An investigation on maintenance problems of some flood embankments in and around Dhaka city[J]. Indian journal of power and river valley development, 2009, 59(3/4): 38-49. 